\title{
BARTOLOMÉ CAIRASCO DE FIGUEROA Y EL AUTO SACRAMENTAL: LA COMEDIA DEL ALMA
}

\author{
JosÉ ISMAEL GUTIÉRREZ \\ Universidad de Las Palmas de Gran Canaria
}

\begin{abstract}
Resulta difícil, si no imposible, determinar el año exacto en que don Bartolomé Cairasco de Figueroa (1538-1610) compuso la Comedia del Alma, ya que el canónigo grancanario, en la única copia conservada del manuscrito de su obra, no consignó fecha alguna. De la misma manera, tampoco se sabe a ciencia cierta cuándo se escribieron y representaron la Tragedia y martirio de Santa Caterina de Alejandría y la Tragedia de Santa Susa$n a$, del mismo autor, pese a lo cual uno de los pocos que ha estudiado en su conjunto la actividad dramatúrgica cairasquiana, el investigador rumano Alejandro Cioranescu, tuvo sobradas razones para suponer que ésta debió desarrollarse hacia el último tercio del siglo XVI, en concreto entre 1558 y $1597^{1}$.
\end{abstract}

A falta de datos más precisos, hagamos un esfuerzo imaginativo para trasladarnos hasta la celebración del Corpus Christi de un primaveral día de finales de esa centuria en las Islas Canarias. Asistiremos entonces a la puesta en escena, en las inmediaciones de la Catedral de Santa Ana, en la ciudad de Las Palmas de Gran Canaria, de una obra que pretende sacar provecho moral de la pugna que entablan Lucifer y las virtudes cristianas por ganarse los favores del Alma. Y es que la Comedia del Alma, la pieza a la que nos referimos, responde, en líneas generales, a las directrices marcadas por la categoría dramática conocida como «auto sacramental» - según el citado Cioranescu, es uno de los mejores exponentes del géne-

\footnotetext{
${ }^{1}$ Los años corresponden a las fechas de representación de la primera y la última obra teatral que compuso Cairasco: el Entremés para una farsa (1558), de paradero desconocido, y el tampoco localizado texto dramático preparado para la recepción del obispo don Francisco Martínez Ceniceros (1597). Alejandro CIORANESCU, «Introducción» a Bartolomé Cairasco de Figueroa, Obras inéditas. I. Teatro. Santa Cruz de Tenerife: Goya Ediciones, 1957, p. 12.
}

Rlit, LXVI, 131 (2004), 87-98 
ro en la España renacentista ${ }^{2}$-, lo que no constituye un impedimento para que en su título figure la equívoca denominación de «comedia», una nomenclatura provista de un significado actual muy concreto, pero que, como es sabido, durante el Siglo de Oro abarcaba distintos subgéneros teatrales. El marbete «comedia», lo mismo que el de «tragedia», atravesaba en el período aurisecular por un proceso de indeterminación y de polisemia. El término, lejos de tener una acepción rigurosamente delimitada, podía asignarse a creaciones dramáticas de diversa índole, tanto comedias como dramas. Es lo que se observa, por ejemplo, en un autor como Lope de Vega, que, al tiempo que calificaba de «tragedia» a su obra El Duque de Viseo (1615) y de «tragicomedia» a Peribáñez y el Comendador de Ocaña (1614), encuadró bajo el rótulo de comedia a obras tan disímiles como El mejor alcalde, el Rey (cuyo final justiciero haría pensar en la denominación de tragicomedia, lo mismo que Peribáñez) o La dama boba (1617), que, al igual que Casa con dos puertas mala es de guardar, de Calderón de la Barca, o Entre bobos anda el juego, de Francisco de Rojas Zorrilla, conectan más con el modelo de la comedia latina de Plauto y Terencio. De tal ambigüedad caracterizadora se hará eco el Diccionario de Autoridades (en su primera edición, de 1726), que, apoyándose en textos del Siglo de Oro, definía el concepto como cualquier «poema dramático» que se representaba en el teatro ${ }^{3}$.

La confusión denominativa prevaleciente en el siglo de Lope - y ya anunciada desde la centuria anterior ${ }^{4}$ - resulta útil como enfoque metodológico para entender por qué Cairasco, siguiendo la tendencia general, etiquetó tanto a su auto sacramental para la fiesta del Corpus Christi como a la pieza compuesta para recibir al obispo Fernando de Rueda - la conocida como Comedia del recebimiento, de 1582- con unos rótulos que hoy se nos antojan inapropiados, pues, lo mismo desde el punto de vista de la acepción tradicional del vocablo que desde el punto de vista de los meca-

\footnotetext{
${ }^{2}$ Alejandro CioranesCu, «Cairasco de Figueroa. Su vida. Su familia. Sus amigos», Anales de Estudios Atlánticos 3 (1957), p. 333.

${ }^{3}$ Para Bruce W. Wardropper, la causa de dicha imprecisión terminológica radica en que entre los preceptistas de la época se seguía manteniendo el sentido clásico de la palabra (comedia = obra risible) junto al uso popular de llamar comedia al teatro en general (ya se tratara de comedia de enredo, de capa y espada, mitológica, pastoril, etc.). Por ello, concluye el investigador anglosajón, «En el siglo XVII [...] comedia equivalía a drama» (Bruce W. WARDROPPER, «La comedia española del Siglo de Oro», en Elder Olson, Teoría de la comedia, Barcelona: Editorial Ariel, 1978, p. 189).

${ }^{4}$ Lo que aquí planteamos no es un simple problema de nomenclatura, sino de delimitación teórico-práctica de algunos géneros teatrales como formas autónomas. Como ha enfatizado Díez Borque, la pureza genérica en la época no la apoyaba ni la teoría poética ni las expectativas de recepción (José María DíEZ BoRQUE, Teoría, forma y función del teatro español de los Siglos de Oro, Palma de Mallorca: José J. de Olañeta, Editor, 1996, p. 67).
} 
nismos intrínsecos de la obra, la Comedia del Alma no es una comedia al uso, al menos tal y como la entendían las poéticas clasicistas (es decir, representación de la vida civil y privada, cotidiana y doméstica, rural y urbana, de personajes medios, sin grandes fortunas, cuando no rústicos y plebeyos, o bien género dramático elevado, equiparable a la tragedia, menos en el objeto, que atiende a los peores, desde la consideración de lo ridículo), ni tampoco obedece a las caracterizaciones del género hechas por teóricos de nuestro tiempo ${ }^{5}$. No obstante, sin pasar por alto la apropiación indebida de tal etiqueta, cabría reflexionar, con José María Díez Borque, hasta qué grado «sería lícito [...] preguntarse por la incidencia real de la teoría en la práctica de la creación dramatúrgica y en las expectativas de recepción, porque difícil nos resulta saber hasta qué punto y en qué medida un espectador del siglo XVI distinguía o afinaba los grados de teatralidad de diálogos, coplas, autos, farsas, églogas, comedias... que hoy, desde la crítica, podemos delimitar aplicando conceptos teóricos (en lo que le cumple un papel importante a la semiología teatral)» ${ }^{6}$.

Sin lugar a dudas, el público del siglo XVI, incluyendo el insular, como también algunos escritores en la práctica, no siempre fueron capaces de captar sutiles matices de demarcación intergenérica; ahora bien, eso no nos impide admitir, desde la actual teoría literaria, que la Comedia del Alma se inscribe de forma indiscutible en la modalidad dramática denominada «auto sacramental», que en el Quinientos también llegó a llamarse indistintamente «farsa», «coloquio»e incluso «entremés» ${ }^{7}$. El autor canario, al ajustar la mayoría de los elementos teatrales a los parámetros fijados por el género, fue consciente de las pautas que debía seguir para su correcta elaboración, de tal forma que, en virtud del modelo del drama litúrgico, la Comedia del Alma desarrolla un argumento sagrado apto para su representación el jueves posterior al Domingo de la Santísima Trinidad (el primer

\footnotetext{
${ }^{5}$ A pesar de que Aristóteles en su Poetica ya contemplaba la comedia, que definía como una imitación de acciones cotidianas protagonizadas por hombres inferiores, sin grandes virtudes, en un estilo humilde o bajo, y que provoca el efecto estético conocido con el nombre de ridículo, de lo que se aplicó esa denominación a obras con esas características y finales dichosos, el género no merecería para el Estagirita la misma consideración que la tragedia. Tendremos que esperar al Renacimiento para asistir a un verdadero desarrollo de las teorías sobre el género cómico: unas siguen la tradición latina (Evantio y Proclo), otras la griega (Faustus, Robortello) y una tercera vía funde ambas tradiciones (Minturno). Por otro lado, ejemplo moderno de teoría sobre la comedia es el valioso libro de Elder OLSON, op. cit.

6 José María DíEZ BORQUE, Los géneros dramáticos en el siglo XVI (El teatro hasta Lope de Vega), Madrid: Taurus Ediciones, 1987, p. 16.

7 Sobre los problemas genéricos en otra de las obras cairasquianas, la Tragedia de Santa Susana, véase Victoria GALVÁN GONZÁLEZ, «Dramaturgia hagiográfica de Cairasco de Figueroa en el contexto quinientista», en F. J. Blasco, E. Caldera, J. Álvarez Barrientos y R. de la Fuente (eds.), La comedia de magia y de santos, Madrid: Júcar, 1992, pp. 27 y ss.
} 
domingo siguiente a Pentecostés), que es cuando se festeja el Corpus Christi. Por otra parte, al estar orientada hacia el obsequio y la alabanza del sacramento de la Eucaristía ${ }^{8}$, de donde reciben tales obras el nombre de sacramentales, la Comedia introduce en los diálogos cierta apariencia de desenfado y comicidad, que alterna con un trasfondo moralista, además de poner en movimiento un buen elenco de personajes que, lejos de representar a seres humanos, poseen un carácter marcadamente alegórico ${ }^{9}$.

A diferencia de las comedias propiamente dichas, la obra de Cairasco no se divide en actos o jornadas; es una representación concebida sin intermedio, estructurada en diez escenas no excesivamente largas, precedidas por una cuarteta que interpretan unos cantores, seguida de la exposición del argumento (loa en prosa y en verso enunciada por cierto personaje anónimo que, de manera expresiva y empleando tanto fórmulas solemnes como giros populares, pide la atención y la benevolencia del público).

Destaquemos, dentro de la pluralidad temática propia de esta forma teatral (materias bíblicas, vidas y leyendas de santos, piezas alegóricas y teológicas, e incluso temas amorosos y propios de la farsa), el interés de Cairasco por mostrar la redención de un alma descarriada y la lucha infructuosa que mantiene el Demonio por recuperarla para su causa.

Una coordenada de los autos, que no falta en la Comedia del Alma, es la brevedad. Esta característica y la continuidad, denominadores comunes en todo el teatro cairasquiano, nos ponen sobre la pista de una forma determinada de comunicación escena-espectador, marca definitoria del género, que sirve de acicate para el funcionamiento de mecanismos calculados de estímulo-respuesta a través de procedimientos aleccionadores que introducen la risa en el componente «serio» como captatio benevolentiae, distensión y necesario esparcimiento del público ${ }^{10}$.

$\mathrm{Si}$ bien los autos sacramentales suelen estar compuestos en verso, el de Cairasco alterna verso y prosa. En el aspecto métrico, a las habituales

\footnotetext{
${ }^{8}$ Este papel le toca desempeñarlo en la obra de Cairasco al Entendimiento, actante que en la última escena le explica al Alma el misterio del sacramento eucarístico (Bartolomé CAIRASCO DE FIGUEROA, Obras inéditas. I. Teatro, ed. cit., pp. 208-214). Todas las citas de esta obra provienen de esta edición. Las cuatro piezas editadas por el investigador rumano han sido recogidas posteriormente en Canciones de poesías varias: manuscrito 2803 de la Biblioteca Real de Madrid. Ed. de José J. Labrador Herraiz y Ralph A. DiFranco; pról. de Máxime Chevalier. Madrid: Patrimonio Nacional, 1989.

${ }_{9}$ Melveena McKendricK, en su libro El teatro es España (1490-1700) (Palma de Mallorca: José J. de Olañeta, Editor, 1989, pp. 254-278), nos facilita abundantes pormenores sobre las representaciones de los autos sacramentales en España.

${ }^{10}$ El humor impregna, en algunos momentos, todas las piezas dramáticas de Cairasco. Este aspecto en los versos esdrújulos del autor ha sido examinado por Robert $\mathrm{L}$. Hathaway, quien además baraja la hipótesis de la intervención del propio dramaturgo como actor en sus obras teatrales (Robert L. HATHAWAY, «Unos esdrújulos problemáticos de Cairasco de Figueroa», Bulletin of the Comediantes 47.1 [1995], pp. 121-134).
} 
estrofas de arte menor, con importante frecuencia de quintillas y, eventualmente, de cuartetas, coplas y redondillas, que coinciden con las formas líricas populares, situando estas piezas en la órbita extensa de una recepción amplia, el autor canario añadirá una mayor variedad versificadora al combinar con la prosa y las estrofas en versos cortos, distintas estructuras italianizantes de arte mayor, como endecasílabos blancos, octavas reales, serventesios o tercetos encadenados.

$\mathrm{Su}$ estructura dialogística puede ser resultado de una larga tradición de ejercitamiento en la literatura de diálogos y debates ${ }^{11}$, que precisamente en el siglo XVI encuentra un momento de floración también en ricas manifestaciones prosísticas, como las obras de Juan de Valdés Diálogo de doctrina cristiana (1529) y Diálogo de la lengua, inédita hasta 1737, la atribuida a Cristóbal de Villalón, El Crotalón de Chistophoro Gnosopho, no publicada hasta 1871, las de Alfonso de Valdés, Diálogo de Mercurio y Catón (1529) y De las cosas ocurridas en Roma, o la de fray Luis de León, De los nombres de Cristo (1583), entre otras.

Muy frecuentemente, la estructura del diálogo se genera en la técnica de planteamiento de un problema «complejo» o en las connotadas tensiones del amor con rescoldos de angustias de cortesanía, visibles en la «pasión» de Lucifer por el Alma o en el despecho que experimenta el mismo personaje en otra obra, la Tragedia y martirio de Santa Caterina (36-7), cuando en la escena IV se entera de la conversión de la joven alejandrina al cristianismo ${ }^{12}$. Pero quizás uno de los rasgos más comunes y caracterizadores sea la tensión lingüística que surge de un esquema bastante fijo de dramatis personae, escindido polarmente en un plano noble-serio y en otro rústico-cómico, de donde sobreviene una suerte de doble intriga como esquema estructural de la pieza.

El mecanismo de oposiciones, indispensable en la base de la estructura y forma del auto y que divide la galería de personajes en nobles y humildes, redunda en la tipificación emblemática de los mismos. El plano noble-serio (que en el auto puede estar desempeñado por ángeles, figuras bíblicas, Cristo, Virgen, Evangelistas, santos, conceptos, dioses mitológicos, dignos caballeros enamorados con connotados nombres, emperadores, héroes clásicos...) se encarna en la Comedia del Alma en seres que simbolizan las virtudes cristianas. El plano rústico-cómico, dotado de una función cómica, de contraste, amplia y variopinta, y que desempeñan normalmente un pastor, un vaquero, un fraile, un viejo, un bobo, estudiantes, labradores, gitanas, pajes, criados, etc., lo ocupan, por el contrario, en la obra de

${ }^{11}$ Vid. José María DíEZ BorQue, Los géneros dramáticos en el siglo XVI (El teatro hasta Lope de Vega), op. cit., p. 20.

${ }_{12}$ Este hecho despierta las iras del Demonio, que, dolorido y fuera de sí, expresa su desgracia como cualquier enamorado abandonado por la mujer a la que ama. 
Cairasco distintos pecados y vicios humanos que recurren a toda suerte de ardides para doblegar la firme voluntad del Alma después de su reconciliación con Dios.

La convivencia en esta composición dramática de entes corpóreos y abstractos, hechos realidad visible a través de la persona del actor - bipolaridad habitual en los autos sacramentales-, no se registra en la obra cairasquiana (aunque sí en otras del mismo autor), donde sólo intervienen figuras conceptuales hasta un total de veintidós (Inspiración, Divina Lumbre, Libre Albedrío, Alma, Ocio, Murmuración, Consideración, Mala Inclinación, Razón, Pecadillo Venial, etc... ${ }^{13}$. Lo que sí comprobamos es la peculiar articulación que se hace de lo religioso y lo profano como técnica calculada de captación o la coexistencia anacrónica y naturalista de personajes que proceden de universos ideológicos inconciliables o de disímiles tradiciones culturales (es el caso de la inserción del personaje mítico de Orfeo, que, a petición de Lucifer, intenta enternecer con su música al Alma reformada), rasgos definidores todos de la mecánica de los dramatis personae que funciona en este tipo de obras teatrales. Los caracteres, asimismo, quedan definidos por su naturaleza emblemática, por su funcionalidad en la pieza, es decir, se manifiestan de acuerdo con el esquema conceptual previo que les corresponde, sin grandes posibilidades de individualización. El Alma es el único personaje ambiguo, cambiante $\mathrm{y}$, como tal, transita entre dos niveles estructurales opuestos: el infernal y el celestial, decantándose, después de la escena $\mathrm{V}$, por el último.

En cuanto al Diablo, el epíteto de «tenebroso» que le atribuye el Libre Albedrío (150) no halla correspondencia en el caudal de victorias, siempre nulas o momentáneas, que cosecha. En la pieza la figura del Diablo tiene, en parte, algo de dolido amante petrarquista, como hemos apuntado, y también algo de personaje folklórico más que de personaje dramático, como suele ocurrir en multitud de farsas o autos religiosos, donde no se le toma en serio y se aproxima a la figura popular del «coco», mitad bufón mitad espantajo, idóneo para asustar a los niños. El berrinche que experimenta Lucifer al saber que el Alma, con la que había tenido tratos durante un tiempo, ha renegado de su compañía, da pie a continuas situaciones hilarantes que descalifican la imagen terrorífica con que se tiende a asociar a este representante del mal. Los tres emisarios a los que envía para reconquistar el «corazón» del Alma (Hipocresía, que se equipara a la figura tradicional de la alcahueta, un actualizado Orfeo, cuyas dotes musicales han

\footnotetext{
${ }^{13}$ Los planos alegóricos y humano se conjugan a partes iguales en el resto de la producción teatral del escritor canario, incluyendo la famosa Comedia del Recibimiento que se le hizo al Reverendísimo Señor don Fernando de Rueda, que Rafael Fernández Hernández, entre otros críticos, ha analizado brevemente (Rafael FERNÁNDEZ HERNÁNDEZ, «Introducción». Teatro canario, I (Siglo XVI al XX). Antología, Las Palmas de Gran Canaria: EDIRCA, 1991, pp. 19-21).
} 
perdido todo poder sobrenatural, y la Carne, que se bate en duelo con el Espíritu) no consiguen mejor resultado. Lo terrible del diablo es, pues, simple ademán externo, hojarasca verbal, simbología icónica; su existencia establece una maniquea división que lo enfrenta a la superioridad del Divino Príncipe, entidad que no se manifiesta físicamente como el Demonio, sino a través de distintos mensajeros. Con su ingenua maldad, Lucifer cumple la obligada función de desencadenar las acciones, enlazadas una a otras en un proceso de tensiones (de situaciones, de ideas en conflicto) que conduce hacia un desenlace resolutivo con acusado carácter espectacular.

Como era habitual en aquel tiempo, el avance de los acontecimientos es lineal, con escasa complejidad de acción y poco rendimiento de las coordenadas espacio-temporales. En buena medida (y coherentemente con su filiación literaria de origen) se trata de un teatro de la palabra, de la narratividad dicha ${ }^{14}$, en el que la acción y las situaciones son el resultado visible de los diálogos, sin apenas utilizar las variadas posibilidades de contrastes entre lo que se dice y lo que se hace, lo aparente y lo real, lo que es y lo que parece..., que, en buena medida, será la apoyatura del teatro posterior.

La escasez de acotaciones proporcionadas por el dramaturgo nos hace pensar, en principio, en una supuesta simplicidad técnica en el dominio de la representación, representación que parece incidir más en el contenido de las acciones y en el mensaje que transmite que en aspectos muy elaborados de la tramoya o en complicados juegos escénicos. Sin embargo, hay que contar con la progresiva complejidad de los carros, vinculados a la espectacularidad de la fiesta y el gradual enriquecimiento y la evolución de los componentes visuales y decorativos incorporados a lo largo del siglo XVI.

Téngase en cuenta que la Contrarreforma, que reafirmó la importancia de los sacramentos y de otros dogmas sacudidos por la oleada de protestantismo que amenazó con desestabilizar los cimientos de la Iglesia ortodoxa, pondrá el énfasis en lo visual y en los rituales, dando notable impulso al desarrollo del drama religioso alegórico ${ }^{15}$. De acuerdo con esto,

\footnotetext{
${ }^{14} \mathrm{El}$ pilar fundamental del teatro del Siglo de Oro es la palabra. Debido a la parquedad de recursos del código del texto escénico, la escritura teatral, la palabra, pueden sustituir una gama amplia de signos visuales cuando comunican una acción verbal no mostrada ni por signos cinéticos ni de vestuario ni de escenografía. Cfr. José María DíEZ BORQUE, «Una aproximación semiológica a la 'escena' del teatro del Siglo de Oro español», en AA.VV. Semiología del teatro. Textos seleccionados por José María Díez Borque y Luciano García Lorenzo. Barcelona: Editorial Planeta, 1975, p. 56.

15 Vid. James A. PARR, «La época, los géneros dramáticos y el canon: Tres contextos imprescindibles», en AA.VV. El teatro en tiempos de Felipe II. Actas de las XXI Jornadas de teatro clásico de Almagro, julio de 1998. Ed. de Felipe B. Pedraza Jiménez y Rafael González Cañal. Almagro: Ediciones de la Universidad de Castilla-La Mancha/ Festival de Almagro, 1999, pp. 121-122.
} 
la integración de la pieza en una ceremonia extrateatral, como era la celebración del Día del Corpus, viene a confirmar, lo mismo que las obras pensadas para homenajear a alguien y escenificadas en las recepciones de personalidades políticas o eclesiásticas ${ }^{16}$, que la representación dramatúrgica aurisecular constituía una parte imprescindible de tal ceremonia, convirtiéndose ella misma en lo que se podría denominar con el término de rito. Tanto en la propia estructura del género como en sus orígenes, vinculados a procesiones y prácticas festivas de celebración del Corpus, el auto sacramental se define como una forma de culto, de ritualización litúrgica, de ceremonial celebrativo que le devuelve «al teatro su verdadera naturaleza, tan largamente desfigurada por prestar atención excluyente a lo 'literario', a lo textual, olvidando su inaplazable 'fisicidad', es decir, la representación, como algo que pertenece a la esencia y no es un accidente» ${ }^{17}$. $\mathrm{Y}$ aun echando de menos una mayor presencia del discurso autorial - a no ser que entendamos por tal todo lo que no es diálogo (nombre de los personajes, título, división en escenas, etc.), es decir, el «para-texto» del que habla J.-M. Thomasseau o el «cotexto» según Kurt Spang ${ }^{18}-\mathrm{y}$ de otros signos escénicos directos, es notorio lo esporádico de aquellas informaciones relativas a la acción de los personajes (entradas, salidas, canciones, si bien, en ocasiones, se refieren también al vestido caracterizador y a la utilería ${ }^{19}$ ) que se deslizan en la escritura, lo que parece mostrar una etapa de rudimentaria teatralidad, en que los parlamentos pasan de la simple recitación a su puesta en movimiento, con elementos complementarios (música, danza...) pero sin un desarrollo importante de lo escenográfico, que vendría delimitado por el espacio de la iglesia o del tablado callejero.

${ }^{16}$ Aparte de la Comedia del recebimiento que se le hizo al Reverendísimo Señor don Fernando de Rueda, obispo de Canarias, Cairasco, que se sepa, escribió otros tres textos conmemorativos: una comedia representada en el recibimiento del obispo don Fernando Suárez de Figueroa (1588), otra, ya mencionada, que se puso en escena con motivo de la llegada del obispo don Francisco Martínez Ceniceros (1597), ambas perdidas, y una cuarta representada al obispo de Canarias don Cristóbal Vela (1576), aún inédita y cuyo manuscrito, según reseñan Agustín Millares Carlo y Manuel Hernández Suárez, se halla en la Real Academia de la Historia (Agustín Millares CARLo y Manuel HernándeZ SuÁrez. Biobibliografía de escritores canarios (siglos XVI, XVII y XVIII). Con la colaboración de Antonio Vizcaya Cárpenter y Agustín Millares Sall. vol. II. Valencia/Las Palmas: El Museo Canario/Excma. Mancomunidad de Cabildos de Las Palmas, 1977, p. 126).

17 José María DíEz BoRQue, Teoría, forma y función del teatro español de los Siglos de Oro, op. cit., p. 136.

18 J. M. THOMASSEAU, «Para un análisis del para-texto teatral (Algunos elementos del para-texto hugolino)», en AA.VV. Teoría del teatro. Comp. e introd. de María del Carmen Bobes Naves. Madrid: Arco/Libros, 1997, pp. 84-7; Kurt SPANG, Teoría del drama. Lectura y análisis de la obra teatral, Pamplona: Eunsa, 1991, pp. 49-56.

${ }^{19}$ En una acotación en la escena I se dice que el personaje que recita el «argumento» hace una pausa para quitarse un pobre balandrán que llevaba puesto y quedarse vestido con un lujoso traje (142). 
Recursos que garantizan y orientan la comunicación «escena»-espectador, convertidos por imperativo de la costumbre en marca genérica, son los prólogos, introitos, argumentos o loas versificadas o en prosa, atendiendo éstos más a la lectura que a la representación. Los argumentos o introitos, piezas breves indesligables de la obra general en las que se insertan, tienen un valor explicativo, introductorio, de toma de contacto, siendo además una fuente de comicidad, lo que - en una suerte de articulación de lo dulce y lo útil- ejercería de captatio benevolentiae del espectador. Forma tipificada de apertura, la loa se une, coherentemente, a la de cierre: un villancico, una canción, que dan fin a la obra, estructura ésta de aperturaauto-cierre que deviene en un elemento genérico definidor de la pieza y que hace también de la Comedia del Alma un ejemplo modélico - aunque poco conocido- de auto sacramental gestado en suelo isleño.

A propósito de las estrategias de cierre, las canciones finales se intercalan en varios lugares de la composición: en la introducción, al concluir las escenas I, la IV, la V y la IX. Al respecto, se observa la pervivencia del texto cantado al término de los autos o de algunas de sus partes intermedias, lo que no se explicaría solamente por la búsqueda de un espectáculo integrador, sino también por los factores de proyección y de reconocimiento que supone para el espectador reencontrar estructuras y formas conocidas, que pertenecen a la cultura de sus canciones, la lírica popular.

Tras aislar aquí algunas peculiaridades generales de la obra, no nos cabe la menor duda de que la Comedia del Alma se identifica grosso modo con las fórmulas tipológicas del género del auto, si bien, como ha anotado Cioranescu, la ficción alegórica del tema eucarístico, a excepción del enfrentamiento en la escena IX entre la Carne y el Espíritu, que rivalizan para apoderarse del Alma, parece ser invención del poeta ${ }^{20}$.

Un rasgo que comparte la Comedia del Alma con los demás textos cairasquianos es, junto con la humanización de personajes que encarnan conceptos abstractos, la proliferación de menciones a lo inmediato y cercano. En este caso, tanto uno como otro dispositivo actúan como estrategias que se hacen eco del deseo de lograr de forma amena cierta impresión de concreción al amparo de un esquema dramático que hace de lo conceptual y de las tensiones ideológicas su principal baza estructurante.

Lo vemos en el diálogo entre el Ocio y la Murmuración, donde el primero le dice al otro que viene «de la puerta de Learda» y que se va a sentar «al banco Sant Martín» (159), mientras que la segunda figura le propone ir a pasear a los Álamos (160), espacios que cualquier habitante de la capital grancanaria de la época podía reconocer perfectamente. En el momento en que el Ocio le pide a la Murmuración su opinión sobre la

${ }^{20}$ Observación de Alejandro CIORANESCU en «El teatro de Cairasco». Estudios de literatura española y comparada, La Laguna: Universidad de La Laguna, 1954, pp. 72-73. 
gente de esta tierra, ésta contesta que «muchos de los hombres de aquí son de casta de ranas, que cantan en viendo la noche; y en viendo la falta de alguno, séase quien se fuere, luego ha de salir a la plaza; y, si se tiene alguna virtud, la callan o la deshacen» (161-2). El Ocio, por su parte, no pierde la ocasión para jactarse de lo bien recibido que es en la isla: «Lo que yo mando, eso se hace; y al fin no se hace nada, que es lo que yo quiero. Y, si en Canaria se diese saca de tiempo, todos serían ricos» (162), palabras que Murmuración refrenda con los siguientes argumentos: «Si en Canaria hubiese hombres, ¿habíamos de comer el aceite estilado por alquitara, como agua de ángeles? Si Canaria [sic] hubiera hombres, ¿habíamos de comprar el pan por cedulillas? Tierra es la de Canaria, donde se podría dar de lo necesario para la vida humana, si la ociosidad no lo estorbase» (162). Más adelante, la Mala Inclinación intenta seducir al Alma con varios presentes, entre ellos ámbar hallado en Guanarteme (171), un barrio costero de la ciudad de Las. Palmas.

Amonestaciones explícitas o veladas afloran irónicamente en labios de varios personajes, sobre todo de aquellos que representan los vicios y defectos humanos que luchan por hacer valer sus derechos. Pecado, por ejemplo, propone conquistar al Alma con un soneto o con música, a lo que Lucifer, enfurecido, le responde:

$$
\begin{aligned}
& \text { Dime, traidor, ¿estamos aquí en Nápoles? } \\
& \text { ¿No sabes que en Canaria esto de Méjico, } \\
& \text { estos reales de Columnas de Hércules } \\
& \text { valen más que la ciencia y la retórica } \\
& \text { de Cicerón, Virgilio y Demóstenes } \\
& \text { y que de Orfeo la sonante cítara? (185). }
\end{aligned}
$$

Por lo que, en vez de un poema o una composición musical, le encarga al Pecado que la seduzca con el ofrecimiento de riquezas materiales.

Idénticas alusiones a la realidad canaria y atribuciones a los espectadores de un papel activo o la solicitud de que invadan lo que se conoce como «cuarta pared» quedan patentes en la escena V. El Regalo, pensando en el público, afirma: «Osaría yo jurar que hay pocos en el auditorio, que no [me] quieran bien» (188). La Hipocresía, al divisar al Regalo, exclama: ¡Válgame Dios, el Regalo del mundo en Canaria!»; ésta, a su vez, al ver a aquélla, grita de la misma guisa: «iVálame Dios! ¡La hipocresía del mundo en Canaria!» (189). Por citar un último ejemplo, la Hipocresía se admira de encontrarse a Regalo en una tierra «tan corta», «tan pobre, hambrienta y mísera» como las inapropiadamente denominadas Islas Afortunadas $(190)^{21}$. Visto todo lo cual, cobra sentido el siguiente aserto de Salva-

${ }^{21}$ Como anota A. Cioranescu, todo ello confirma el «realismo» del teatro del escritor, «que no desentona con la abstracción de los personajes alegóricos» (ibidem, 
dor F. Martín Montenegro acerca de algunas de las señas de identidad de la Comedia del Alma:

El carácter alegórico que caracteriza a los autos sacramentales y piezas afines se atempera en Cairasco gracias a la naturalidad del discurso de los personajes y a la humanidad misma con que actúan. La inserción de múltiples detalles cotidianos o referencias a la actualidad humanizan lo abstracto y lo hacen entrañable y propio. Lo local no parece forzado, lo que no deja de ser un logro atendiendo al carácter simbólico, laudatorio y sacramental de sus composiciones. Además, estas especificidades, intercaladas conscientemente para agradar al auditorio, resultaban muy eficaces con intención satírica y moralizadora o simplemente cómica» ${ }^{22}$.

En efecto, la habilidad para plantear problemas teológicos, recurriendo a ingredientes simbólicos y alegóricos unidos a formas satíricas y cómicas y el haber podido resolver con soltura la alternancia de lo abstracto y atemporal con frecuentes guiños a la inmediatez isleña contemporánea constituyen dos de los mayores aciertos de la obra de la que nos hemos ocupado.

p. 76). Ejemplo de este realismo es también el retrato de la alcahueta al principio de la escena VII: «HIPOCRESÍA. [...] Cada hora ponemos la vida al tablero; a cada paso aventuramos la honra. Aquí nos afrentan, allá nos maltratan, oímos malas palabras, sufrimos peores obras; y todo por dar contento a ruines. Y lo peor es que, como el día de hoy cada una vive por su pico, es tan poco lo que se gana, que en una ida y una venida a casa del pardo, allá va la ganancia de un año. Con todo eso, he de sustentar mi honra y defenderla con palabras y apariencias exteriores, fingir tristeza en el rostro, abemolar la voz, los ojos en el suelo, las cuentas en la mano, a pregonar vino y en efecto vender vinagre $[\ldots] »(189)$.

${ }^{22}$ Salvador F. MARTín MONTENEGRo, «El teatro en Canarias, siglos XVI y XVII», en AA.VV. Historia crítica Literatura Canaria. vol I. De los orígenes al siglo XVII. Coordinado por Yolanda Arencibia y Rafael Fernández Hernández. Las Palmas de Gran Canaria: Ediciones del Cabildo de Gran Canaria, 2000, p. 484. 


\title{
RESUMEN
}

Bartolomé Cairasco de Figueroa y el auto sacramental: la Comedia del Alma, por José Ismael Gutiérrez.

La Comedia del Alma, de Bartolomé Cairasco de Figueroa, pese a su título, pertenece al género dramático conocido como «auto sacramental». No sólo es uno de los escasos autos sacramentales escritos en las Islas Canariàs, sino que además es uno de los mejores del siglo XVI español. La pieza teatral se ajusta en muchos aspectos a las características del género: mezcla lo serio y lo cómico, lo abstracto y la humanización, lo culto y lo popular, la prosa y el verso... Pero quizás la mayor particularidad de la obra sean las referencias a la realidad inmediata de los espectadores que aparecen en ella y las críticas que algunos personajes alegóricos hacen de las costumbres de la sociedad canaria de la época.

Palabras clave: Literatura canaria, Teatro español del Siglo de Oro, Auto sacramental.

\begin{abstract}
In spite of its title, Comedia del Alma, by Bartolomé Cairasco de Figueroa, is an allegorical religious play. This literary work not only is an inusual testimony of this gender in Canarian Islands; it's also one of the best allegorical religious plays of the Spanish Renaissance. Comedia del Alma alternates between humor and seriousness, abstract ideas and humanization, learned and popular style, verse and prose. However, its principal characteristic concerns the allusions which the characters make to the reality close to the audience and the fierce attack launder on the Canarian society.
\end{abstract}

Key words: Canarian Literature, Golden Age Spanish Theatre, Allegorical religious play. 